\title{
Competence Mapping through Analysing Research Papers of a Scientific Community
}

\author{
Antonio P. Volpentesta and Alberto M. Felicetti \\ Department of Electronics, Computer Science and Systems, \\ University of Calabria \\ via P. Bucci, 42\C, 87036 Rende (CS), Italy \\ \{volpentesta, afelicetti\} adeis.unical.it
}

\begin{abstract}
Main goal of a scientific community is the collaborative production of new knowledge through research and scholarship. An integrative research approach, fostered by confrontation and collaboration among researchers, is widely recognized as a key factor to improve the quality of production of a scientific community. Competence mapping is a valid approach to highlight expertise, encourage re-use of knowledge, contributing significantly to the growth of the scientific community. In this paper we propose a methodological framework for examination and semi-manual classification of research papers. This method leads to the creation of a database that correlates research competences and researchers.
\end{abstract}

Keywords: Competence mapping, scientific community, collaborative knowledge, classification of research papers.

\section{Introduction and Theoretical Background}

Competence is a concept widely recognized in scientific literature since the early of 20th century, and particularly stressed in human resource management [1],[2]. Formally, competence is understood as the relation between humans and work tasks, specifically, which knowledge and skills are required to perform a specific task in an efficient way [3]. The concept of competence is related to the concept of competency; in [4] a competency is defined as "a specific, identifiable, definable, and measurable knowledge, skill, ability and/or other deployment-related characteristic (e.g. attitude, behavior, physical ability) which a human resource may possess and which is necessary for the performance of an activity". In [5], in the effort of univocally identify HR concepts, authors define a competency as "the proven ability to use knowledge, skills and personal, social and/or methodological abilities, in work or study situations and in professional and personal development", while a competence as "a competency (knowledge + skills + abilities) in a particular context (e.g, situation, domain)". An effective competences management within an organization, i.e. oriented to the continuous enhancement and development of individual and organizational competences, requires as first and necessary step the mapping of organization competences. A Competences map can be defined a representation of key competences of each member of an organization [6]; it represents a valuable tool for identifying members of an organization who possess competences to perform a task. A competences map 
facilitates efficient knowledge sharing between organizational members, constituting a multifaceted approach for creating structure out of an overabundance of potentially useful information [7],[8].

Traditional approaches in building competence maps are based on tools such as questionnaires or assessment sessions that allow organizations to define professional profiles of employees[9], [10]. In recent years, novel approaches based on document content analysis are taking place. Relational Content Analysis (RCA) approach, for instance, deals with extracting the relationships between actors, issues, values and facts from texts, for example relationships of support/criticism or cooperation/conflict between actors, subjective causal relationships between issue developments, or relationships between contents and actors [11]. Honkela et al. [12] claim that adaptive tools for data and text mining can be particularly useful in competence management enabling a more efficient process that can be based on a variety of heterogeneous sources of information.

Besides being important in the business oriented organizations, competence mapping is recognized to be important in many contexts. One of the most interesting, is the academic environment where competence mapping may provide a fruitful avenue for intellectual capital management [8]. In such context, and in particular within the scientific community focused on collaborative production of new knowledge, a problem currently faced is the inability of an organizations to know the competences owned by their members which prejudices the multi-disciplinary research and community creation [13].

A scientific community (also called epistemic community) is a collaborative network of professionals with recognized expertise and competence in a particular domain; such network defines policies for the collaborative creation of new knowledge within the target domain or issue-area [14]. Community members come from a variety of disciplines and backgrounds, having a shared set of normative and principled beliefs and a set of defined criteria for weighing and validating knowledge in the domain of expertise. As stated by Shur et al. [15], collaboration is the essence of science and is a key factor in scientific knowledge construction.

Unfortunately, collaboration in science is often reduced to the level of interpersonal knowledge. Scholars are not aware of other researchers who are working on similar projects thus collaboration frequently occurs among a small number of people working in the same group, dealing with or researching more specific items of their domain. A valid approach to highlight capabilities within a scientific community and suggest new collaborations between researchers may be the construction of a community competence map. This approach was already adopted by several authors. Rodrigues et al. [13] discuss about methods and techniques applied to the area of knowledge discovery from texts, in order to mapping researcher's competence in his/her publications. Janasik et al. [16] demonstrate the use of a self-organizing map method, a quantitative method for text mining, directed to organizational researchers interested in the use of qualitative data. In Vatanen et al. [17] a web environment is presented, called SOMPA (Self-Organizing Maps of Papers and Authors), for collecting and analyzing information on authors and their papers. None of these scholars faces up to the problem of defining research competences within a scientific community and to survey them by analysing the scientific production of community members. In this paper, the authors want to fill this gap proposing an original approach to map research competences 
within a scientific community. The research approach makes use of a competence representation model, based on a logical structure of directed hypergraph [20], within a collaborative semi-manual mapping process.

\section{Contribution to Sustainability}

Usually the concept of sustainability is related to the use of a regenerative natural system in such a way that this system retains its essential properties [27]. However, in our concern, sustainability is defined as the infrastructure that remains in a scientific research community after the completion of research projects [28].

The goal of a scientific research community is to add new knowledge to that currently available in a particular field of inquiring, including the long-term maintenance of effects of new knowledge and fostering of collaboration between researchers. New scientific knowledge only becomes relevant to society, if it spills over. The concept of sustainability, in this terms, involves organizations that modify their actions as a result of participating in research, and individuals who, through the research process, gain knowledge and skills that are used in real world economic domains. Sustainability is more than the continuation of a research intervention, it concerns the possibility of maintaining or increasing effects achieved during a research phase. From this point of view, a more rational use of scientific competences certainly contribute to a more efficient approach in establishing a sustainability orientation of scientific research.

In this sense, research competences constitute an important component of sustainability as a part of the infrastructure that remains in a scientific research community after the completion of research projects.

An outcome of sustainability is the exchange of knowledge. Competence maps enable this exchange by making more effective and sustainable research collaborations and the development of new scientific questions and methods, [29].

\section{Research Approach}

Research is "an activity that aims to discover, interpret and revise in a non-trivial way, facts, events and theories, using a methodological approach in order to add new knowledge to that currently available, leading to new insights or improving the use of knowledge already available" [18]. This knowledge should be a wealth of structured information, easily accessible and of long-lasting value [19].

According to [5] definition of competency, we can define a research competency as "the proven ability to use knowledge, skills and personal, social and/or methodological abilities in conducting a research in a scientific domain".

In this study, we use the terms :

- Research competence ( $R C$ ), as a "research competency" in a specific field of inquiring.

- Researcher competence profile, as the set of all research competences owned by a researcher.

- Research competence map, as a representation of a set of researchers competence profiles. 
In what follows, a detailed description of an approach aimed to survey the research competence map for a selected scientific community is given. As stated before, the basic assumption for the approach is that it's possible to highlight the research competences of a researcher, and thus its competence profile, by analysing the researcher's scientific production (published papers). The approach is made of two fundamental parts: a competence representation model and a structured mapping process.

\section{Competence Representation Model}

Any scientific community is characterized by its own concept of research competence. Anyway, it is possible to affirm that generally a scientific community adopts a set of types of research and a scientific method on specific research fields of inquiring. This allows to affirm that a RC is strictly associated with a triple (t, p, s), where:

- $\mathrm{t} \in \mathfrak{J}$, a set of Research Types;

- $\mathrm{p} \in \mathcal{P}$, a set of phases of an inquiry method;

- $\mathrm{s} \in \delta$, a set of research subjects which are shared by the scientific community

In order to map competences in a scientific community, a competence representation model is necessary to be introduced. Such a model is used by community experts during the competence mapping process while performing a semi-manual analysis and classification of scientific production (research papers) published by members (researchers) of the selected scientific community. In what follows, we propose a model that is based on a logical structure of directed hypergraph [20] that represents

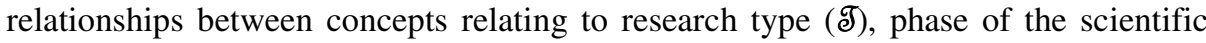
method ( $\mathcal{P})$ and field of inquiry (ฐ).

Any node of the hypergraph fall into three categories:

- Undeveloped concept node

- Developed concept node

- Concept instantiation node

while any directed hyperedge represents how a concept is developed by connecting a set of nodes (tail of the hyperedge) with a developed node (head of the hyperedge). This means that the concept of RC may be represented by a directed hypergraph $\left(H_{0}\right)$, consisting of a only one directed hyperedge as it is shown in fig. 1 :

The directed hypergraph representation highlights the relationship between the developed concept RC with the undeveloped concepts $\mathcal{J}, \mathcal{P}$, 厄.

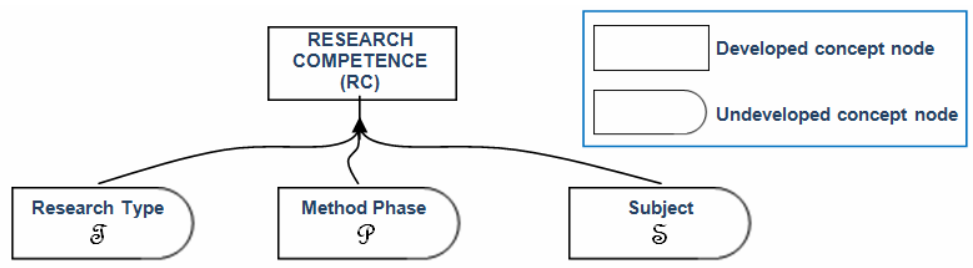

Fig. 1. Research Competence represented as directed hypergraph 
One may recursively use this logical structure to represent the development of undeveloped concept nodes (in fig. $1, \mathcal{J}, \mathcal{P}, \mathcal{\Im}$ ), by introducing concepts instantiation or new concepts to be further developed. In this way we extend the initial $H_{0}$ into a new one $H_{1}$ and so on. This process ends when, at a step $n$, any node that is not the head of any directed hyperedge in $H_{n}$ is an instantiation node. Moreover, if we add a dummy node $s$ and a simple hyperedge $(\{\mathrm{s}\}, \mathrm{x})$ for any instantiation node $\mathrm{x}$, we obtain a $(\mathrm{s}, \mathrm{d})$ hypernetwork [20]; an instantiation of the concept of RC remains associated to a directed hyperpath from $\mathrm{s}$ to $\mathrm{d}$, where $\mathrm{d}$ is the $\mathrm{RC}$ node.

\subsection{A Model Application: The Pro-VE Scientific Community Case}

In order to illustrate the use of the model and the output of the representation process based on it, we may consider the Pro-VE Community, a scientific community that aims to promote research and production of new knowledge on Collaborative Networks [25].

This community adopts a scientific method which can be summarized as follows:

Research type means the type of contribution that is given to the body of available knowledge, the purpose of research and the methodological approaches used while researching. Based on these considerations, we identify the following categories of research:

- Theory (T): Research is focused on generation of new theories (theory building). This kind of research is generally based on an analytical approach that leads to the definition of a model (or a set of models) in order to give an interpretation of the variables involved, and offer predictions that can be verified. This research methodology comprises new insights by developing logical relationships between carefully defined concepts into an internally consistent theory [21]. It usually has low chance of success but, when successful, it has the potential to offer a high contribution to the wealth of knowledge.

- Empirical (E): Taking as a reference to the outcomes of purely theoretical research, research activities are focused on trying to draw general conclusions about the prospects of application, testing of existing theory and, marginally, extend theory. The empirical experimental research uses experimental design to verify the causality of a specific theory while elevating relationships from a testable hypothesis to an empirically verified theory. The outcomes of this kind of research will involve not only researchers and academics in general, but also companies who wish to assess the potential for transfer of results to their applications.

- Practices (P): research conducted with a practical and specific purpose, that aims to generate knowledge in the practical application of theories, developing insightful relationships between scientific research and real world application. It usually involves researchers and practitioners in a particular economic sector. This kind of research generally offers solutions to specific and practical problems, with an high chance of success but with a low contribution in new knowledge.

Phases of the inquiry method, in the case of Pro-VE community, are consistent with the scientific method phases. There are different ways of outlining the scientific 
method used and procedures vary from one field of inquiry to another. However, components of the logical process of a scientific method can be broadly classified in 4 steps $^{1}$ that can be cyclically executed:

1. Characterizations: observation and description of a phenomenon, restating definitions in a new framework, and questioning what is known and what is unknown;

2. Hypotheses: theoretical, hypothetical explanations of observations or models of the subject inquiry;

3. Predictions: drawing consequences or making predictions from the hypothesis or theory, deriving results by means of a method;

4. Tests: conceptually or experimentally testing predictions or results and the path taken to them, measuring the usefulness of a model to explain, predict, and control, and of the cost of use of it.

By taking in consideration such concept developments, considering that the field of inquiring of Pro-VE community concerns the Collaborative Networks $(\mathrm{CN})$, we obtain an extension of hypergraph in fig.1, as it is shown in fig. 2. We can identify a couple $(\mathrm{x}, \mathrm{y})$ where $\mathrm{x}$ is an instantiation of the concept of $\mathcal{J}$, and $\mathrm{y}$ is an instantiation of the concept of $\mathcal{P}$, as a competency in a scientific community, while an instantiation of $\varsigma$ is to be intended as a field of inquiry.

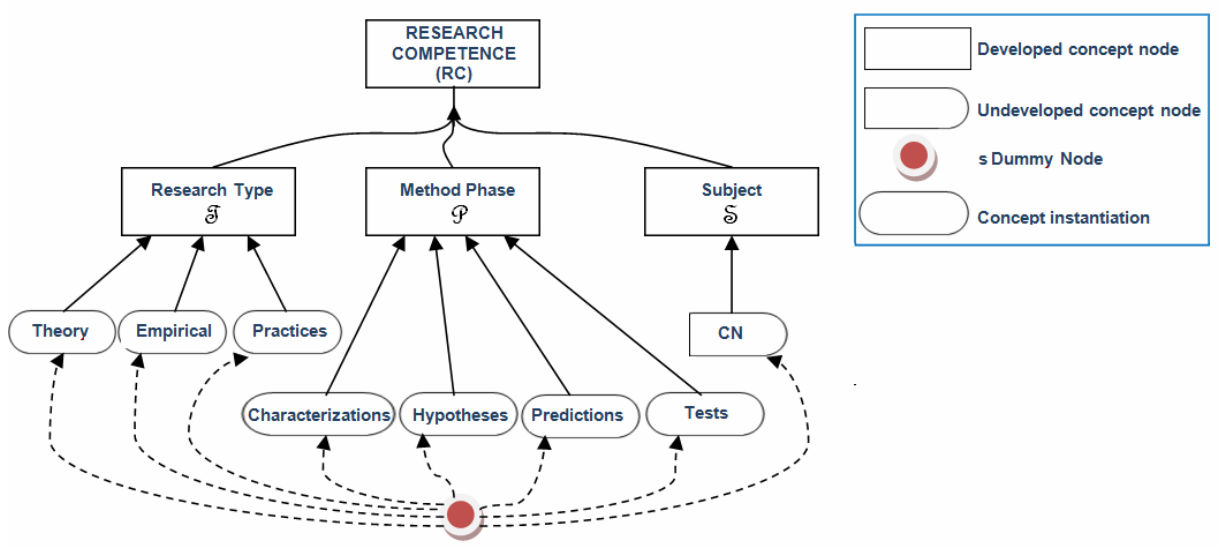

Fig. 2. $\mathrm{H}_{1}$. First instantiation of the hypergraph in fig. 1 to the case of the Pro-VE community.

Any hyperpath in the (s,d)-hypernetwork in Fig.2 is univocally identified by a triple $(x, y, z)$ where $(x, y)$ represents an instantiation of a scientific research competency and $\mathrm{z}$ is an instantiation of the concept of $\delta$.

To each pair $(\mathrm{x}, \mathrm{y})$ is associated a competency as showed in the following table:

A RC is a competency in a given field of inquiring. In order to show how RCs are represented in the model we may further develop the Hypergraph $\mathrm{H}_{1}$. Next level $\mathrm{H}_{2}$ can be obtained by developing the undeveloped node $\mathrm{CN}$. In the field of $\mathrm{CNs}$, a research

${ }^{1}$ This terminology is mainly used in natural sciences and social sciences. In mathematical sciences the terms "understanding", "analysis", "synthesis" and "review/extent" tend to be preferred in describing the method components, (Pólya,1957). 
Table 1. Competencies Matrix for a generic scientific community

\begin{tabular}{|c|c|c|c|c|}
\hline & Characterization & Hypotheses & Predictions & Tests \\
\hline Practices & $\begin{array}{l}\text { Finding and critically } \\
\text { reviewing the } \\
\text { background knowledge } \\
\text { in a search for items } \\
\text { that might help to put a } \\
\text { theory and research } \\
\text { results into practice. }\end{array}$ & $\begin{array}{l}\text { Identifying a practice } \\
\text { problem and } \\
\text { formulating a general } \\
\text { research question or } \\
\text { model appropriate to } \\
\text { this problem. }\end{array}$ & $\begin{array}{c}\text { Providing innovative or } \\
\text { exemplary practices, } \\
\text { models or methods in } \\
\text { communities, } \\
\text { workplaces, } \\
\text { organizations and the } \\
\text { like. }\end{array}$ & $\begin{array}{l}\text { Empirically validating } \\
\text { and evaluating a model } \\
\text { or a method in actual } \\
\text { scenarios and } \\
\text { examining its impact } \\
\text { on current practices. }\end{array}$ \\
\hline Empirical & $\begin{array}{l}\text { Understanding an } \\
\text { inquiry process of } \\
\text { applying or testing a } \\
\text { given theory under } \\
\text { different perspectives } \\
\text { or assumptions. }\end{array}$ & $\begin{array}{c}\text { Generate research } \\
\text { questions for a given } \\
\text { theory by formulating } \\
\text { research hypotheses } \\
\text { (e.g . causal mechanism } \\
\text { or a mathematical } \\
\text { relation) }\end{array}$ & $\begin{array}{l}\text { Using hypotheses to } \\
\text { predict the existence of } \\
\text { other phenomena, to } \\
\text { predict quantitatively } \\
\text { the results of new } \\
\text { observations, or to } \\
\text { draw some testable } \\
\text { consequences. }\end{array}$ & $\begin{array}{l}\text { Setting and performing } \\
\text { empirical tests of an } \\
\text { hypothesis or its } \\
\text { consequences and } \\
\text { evaluating them in the } \\
\text { light of their } \\
\text { compatibility with both } \\
\text { the background } \\
\text { knowledge and the } \\
\text { fresh empirical } \\
\text { evidence. }\end{array}$ \\
\hline Theory & $\begin{array}{l}\text { Reflecting upon one or } \\
\text { more bodies of } \\
\text { scientific literature or } \\
\text { systems of thought and } \\
\text { exploring the value of } \\
\text { different theories and } \\
\text { conceptual tools. }\end{array}$ & $\begin{array}{l}\text { Providing theoretical } \\
\text { evidence of important } \\
\text { issues in identifying an } \\
\text { explanatory gap in } \\
\text { some theories. }\end{array}$ & $\begin{array}{c}\text { Proposing and } \\
\text { developing through } \\
\text { logical reasoning a } \\
\text { theoretical framework } \\
\text { or concept in filling an } \\
\text { epistemic gap. }\end{array}$ & $\begin{array}{l}\text { Conceptually testing a } \\
\text { theory, that is, checking } \\
\text { whether results are } \\
\text { compatible with the } \\
\text { bulk of the existing } \\
\text { knowledge on the } \\
\text { matter. }\end{array}$ \\
\hline
\end{tabular}

topic concerns the study of a "Dimensional Aspects (concept substantially derived from the reference model described in [22]) of a CN Organizational Forms (derived from the classification provided in [23]; this study may relate or not an application in a economic sector in real business environments, where $\mathrm{CN}$ models, mechanisms, methodologies, principles and supporting tools are instantiated and implemented. Therefore the $\mathrm{CN}$ node can be developed as follows:

At this level, a RC is a competency in the study of a Dimensional Aspects of a CN Organizational Forms, or a competency in the study of a Dimensional Aspects of a CN Organizational Forms related to a particular economic sector.

Future developments of the Hypergraph lead to a more detailed representation of RCs.

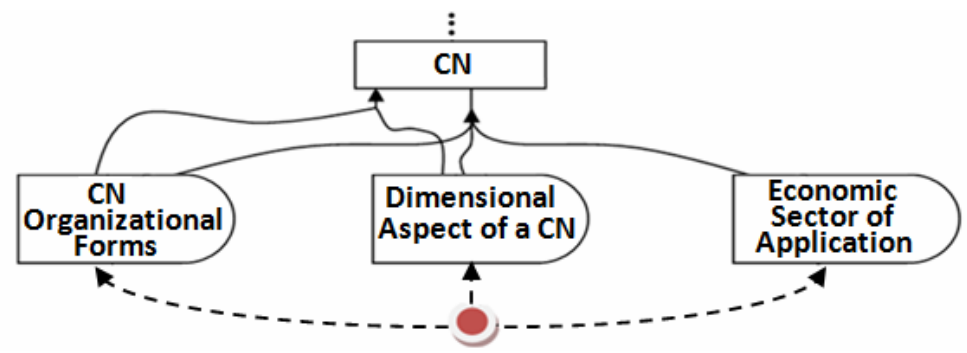

Fig. 3. Development of the research subject "Collaborative Networks" $(\mathrm{CN})$ as represented in fig. 2 


\section{The Mapping Process}

The mapping process is aimed to build a research competence map of a scientific community, that is to say a representation of relationships between research competences and researchers belonging to a scientific community.

This process uses the following inputs:

- Competencies Matrix for a generic scientific community.

- Initial Competence representation model for a scientific community $\left(H_{0}\right)$

- A list of researchers (authors).

- A set of scientific papers.

and provides the following outputs:

- A representation of relationships between research competences and researchers (community research competences map).

- A final Competence representation model for the scientific community $\left(H_{n}\right)$.

The mapping process is based on the analysis of the scientific papers, performed by a team of expert. This methodological framework suggests that a steering committee, possibly formed by senior members of the scientific community who joined it since the beginning of its activities, is charged to define rules to both choose community experts (analyzers) and assign them papers to analyze.

The analysis of each scientific paper is based on three dimensions: the research approach adopted (Research Type), the phase of the scientific method (Method Phase) and the field of inquiry (Subject), according to Hypergraph competence model.

Supported by Competency Matrix, each expert have to individuate the competencies associated to the analyzed paper. In order to recognize the subject of the paper, each analyzer have to find opportune keywords associated to the concepts in the $H_{k}$ competence model, through a semantic analysis of the papers' content. During the process, the competence model could be recursively updated to a more complete version.

This process allows to identify a set of RCs related to each paper. By assuming that research competences of any researcher are manifested on documents whose he is an author, is easy to associate to each researcher a list of RCs.

In order to map competences in a scientific community, we propose a model whose underlying logical structure is a vertex-hyperedge multi-hypergraph $\mathscr{H}(R, \mathcal{E})$. The components of the model are:

- $\quad \mathrm{R}=\left\{r_{1}, \ldots, r_{m}\right\}$ an ordered set of researchers (authors), members of a scientific community;

- $\quad \mathrm{SC}=\left\{\mathrm{sc}_{1}, \ldots, \mathrm{sc}_{n}\right\}$ an ordered set of scientific research competences

- $\quad A \in R^{m \times n}$ a binary matrix that represents the relationships between researcher $\mathrm{r}_{i}$ and research competence $\mathrm{sc}_{\mathrm{k}}$, i.e.: $a_{i k}=1$, if researcher $\mathrm{r}_{i}$ has the research competence $\mathrm{sc}_{\mathrm{k}}$, otherwise $a_{i k}=0$.

$\mathcal{E}=\left\{E_{1}, \ldots, E_{n}\right\}$; , with $\mathrm{Ej}=\mathrm{E}(\mathrm{scj})=\left\{\mathrm{r}_{i} \in \mathcal{R}: \exists \mathrm{k}\right.$ such that $\left.a_{i k}=1\right\} . \mathrm{E}_{j}$ is a subset of $\mathcal{R}$ consisting of all researchers that share the research competence $\mathrm{sc}_{j}$. Of course, a researcher may have many research competences and many research competences may be shared by the same subset of researchers (this is the reason why $\mathscr{H}$ is a multi-hypergraph). 


\begin{tabular}{|c|c|c|c|c|c|c|c|}
\cline { 2 - 8 } \multicolumn{1}{c|}{$\mathbf{A}$} & $\mathrm{E}_{1}$ & $\mathrm{E}_{2}$ & $\mathrm{E}_{3}$ & $\mathrm{E}_{4}$ & $\mathrm{E}_{5}$ & $\mathrm{E}_{6}$ & $\mathrm{E}_{7}$ \\
\hline $\mathrm{r}_{1}$ & 1 & 1 & 0 & 0 & 0 & 0 & 0 \\
\hline $\mathrm{r}_{2}$ & 0 & 1 & 1 & 0 & 0 & 0 & 0 \\
\hline $\mathrm{r}_{3}$ & 0 & 1 & 1 & 0 & 0 & 0 & 0 \\
\hline $\mathrm{r}_{4}$ & 1 & 0 & 0 & 0 & 0 & 0 & 0 \\
\hline $\mathrm{r}_{5}$ & 0 & 0 & 0 & 1 & 0 & 0 & 0 \\
\hline $\mathrm{r}_{6}$ & 0 & 0 & 0 & 1 & 0 & 0 & 0 \\
\hline $\mathrm{r}_{7}$ & 0 & 0 & 1 & 1 & 0 & 0 & 0 \\
\hline $\mathrm{r}_{8}$ & 0 & 0 & 1 & 0 & 0 & 0 & 1 \\
\hline $\mathrm{r}_{9}$ & 0 & 0 & 0 & 0 & 1 & 1 & 0 \\
\hline $\mathrm{r}_{10}$ & 0 & 0 & 0 & 0 & 1 & 1 & 0 \\
\hline $\mathrm{r}_{11}$ & 0 & 0 & 0 & 0 & 1 & 1 & 0 \\
\hline $\mathrm{r}_{12}$ & 0 & 0 & 0 & 0 & 0 & 0 & 1 \\
\hline
\end{tabular}

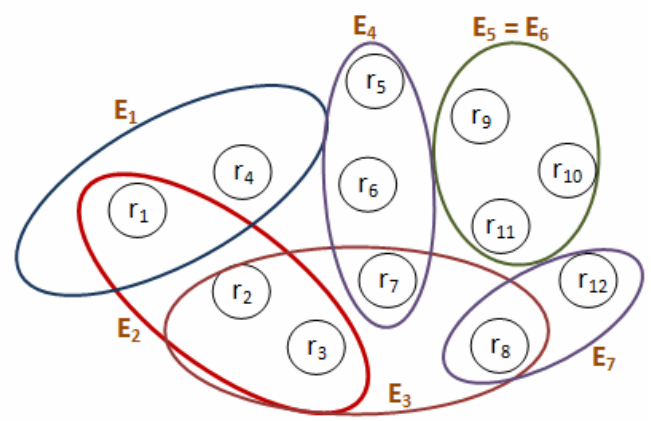

Fig. 4. Example of research competence map

In order to better clarify the mapping process, we present a representation based on 3 phases according to the IDEF0 notation [24]:

\subsection{Phase 1: Activities Planning}

- Actors and roles: a steering committee, possibly formed by senior members of the community who joined it since the beginning of its activities, is charged to define rules to both choose community experts (analyzers) and assign them papers to analyze, the rules for paper analysis, and a software tools that support the activity of analysis.

- Inputs: list of all researchers gathered around the community and, for each of them, the published papers;

- Controls: rules to choose analyzers, rules to assign papers to analyzers

- Mechanisms: steering committee.

- Outputs: list of analyzers, assignment of papers to analyzers, paper classification procedure;

\subsection{Phase 2: Paper Analysis}

- Actors and Roles: analyzers, charged to apply paper classification procedure in order to analyze the papers in the repository; steering committee, who control and validate outputs of the procedure

- Inputs: Competencies Matrix for a generic scientific community, $H_{0}$, list of analyzers, assignment of papers to analyzers;

- Controls: paper classification procedure.

- Mechanisms: steering committee, analyzers, software tools for papers analysis, papers repository

- Outputs: definitive competence representation model $\left(H_{n}\right)$, database of classified papers

The paper classification procedure is an algorithm that comprises $n$ steps as follows:

Step $k(1 \leq k \leq n)$ : Supported by Competencies Matrix, each analyzer has to process its assigned papers in order to recognize scientific approaches and the phases of scientific 
method present in each paper. Furthermore he extract from each article, the keywords related to the concepts described in $H_{k-1}$.

At the end of this step, each analyzer sends to the steering committee the results of his classification. The steering committee discuss and validate all the new keywords discovered by analyzers at this step and decide how to extend $H_{k-1}$ to $H_{k}$. This extension consists in using the validated new keywords to develop undeveloped concept nodes, by introducing concepts instantiation or new concepts to be further developed.

Step n: When neither further keywords are provided by analyzers or new extensions are defined by the steering committee on $H_{n-l}$ (meaning that any terminal node in $H_{n-1}$ is an instantiation node), then the algorithm terminates and the procedure gives in output:

- $H_{n} \equiv H_{n-1}$, i.e. the definitive competence representation model for the community;

- the set of all papers classified according $H_{n}$, i.e. the database of classified papers;

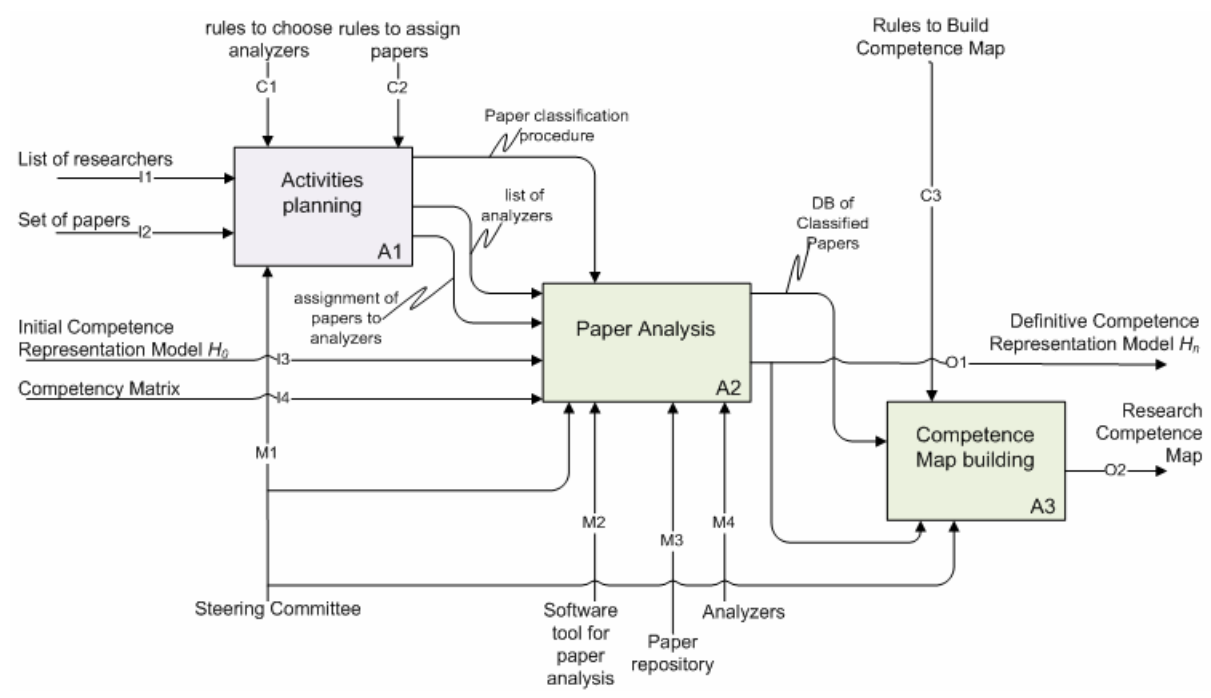

Fig. 5. Graphical representation in IDEF0 notation of the mapping process

\subsection{Phase 3: Competence Map Building}

- Actors and roles: the steering committee, analyzes the classification of scientific papers according to $\mathrm{H}_{n}$ in order to build a research competence map of the scientific community.

- Inputs: database of classified papers,

- Controls: rules to build competence map.

- Mechanisms: steering committee, competence representation model $\left(H_{n}\right)$,

- Outputs: research competence map. 


\section{Conclusions and Future Works}

The presented work is aimed to propose a methodological framework for examination and classification of research papers, useful to build a competence map of a scientific community, relying on the correlation between research competences and researchers. This methodological framework is based on a competence representation model Competence, that is based on a logical structure of directed Hypergraph, to represent the competences present within a scientific community.

In order to represent the competence map of a scientific community, we utilize a multi-hypergraph structure, that models the relationships between researchers and research competences.

An implementation of the proposed research approach will be carry out in order to build a competence map of the Pro-VE community, by examining and classifying the papers published in the last five books related to the Pro-VE Conferences (from 2005 to 2009) [26]. This leads to the creation of a database that correlates research competences and researchers, in order to perform statistical analysis of competences within the PRO-VE scientific community.

\section{References}

1. Taylor, F.: The Principles of Scientific Management. Harper \& Row, New York (1911)

2. Boyatzis, R.E.: The Competent Manager: A Model for Effective Performance. John Wiley and Sons, New York (1982)

3. McLelland, D.C.: Testing for Competence rather than for "Intelligence". American Psychologist 28, 1-14 (1973)

4. Allen, C.: Competencies (Measurable Characteristics), Recommendation of the HR-XML consortium, February 26 (2003), http://ns.hr-xml.org/2_0/HR-XML-2_0/ CPO/Competencies.pdf (March 2010)

5. Vervenne, L., Najjar, J., Ostyn, C.: Competency Data Management (CDM), a proposed reference model. European Commission - Semantic Interoperability Centre Europe (April 2010), http: / / www.semic.eu/semic/view/documents / CompetencyRelated-Data-Management.pdf (retrieved)

6. Draganidis, F., Mentzas, G.: Competency based management: a review of systems and approaches. Information Management \& Computer Security 14(1), 51-64 (2006) ISSN: 0968-5227

7. Wexler, M.N.: The who, what and why of knowledge mapping. Journal of Knowledge Management 5(3) (2001)

8. Hellstrom, T., Husted, K.: Mapping knowledge and intellectual capital in academic envi-ronments: A focus group study. Journal of Intellectual Capital 5(1), 165-180 (2004)

9. Liang, Y., Konosu, T.: A Study on Competency Evaluation of the Members in Software Development Project. Journal of the Society of Project Management 6(2), 29-34 (2004)

10. Yonamine1, R.K., Nakao, O.S., Martini, J.S.C., Grimoni, J.A.B.: A program for the professional development of Brazilian engineering students: origin and development. In: Proceedings of the International Conference on Engineering Education \& Research (ICEE \& ICEER KOREA) (2009)

11. Van Atteveldt, W., Kleinnijenhuis, J., Oegema, D., Schlobach, S.: Representing Social and Cognitive Networks. In: Proceedings of the 2nd Workshop on Semantic Network Analysis, Budva, Montenegro, June 12 (2006) 
12. Honkela, T., Nordfors, R., Tuuli, R.: Document maps for competence management. In: Proceedings of the Symposium on Professional Practice in AI. IFIP, pp. 31-39 (2004)

13. Rodrigues, S., Oliveira, J., Moreira de Souza, J.: Competence mining for virtual scientific community creation. Int. J. Web Based Communities (2004)

14. Haas, P.M.: Epistemic Communities and International Policy Coordination, International Organization. Knowledge, Power, and International Policy Coordination 46(1), 1-35 (1992)

15. Schur, A., Keating, K.A., Payne, D.A., Valdez, T., Yates, K.R., Myers, J.D.: Collaborative suites for experiment-oriented scientific research. Interactions 3, 40-47 (1998)

16. Janasik, N., Honkela, T., Bruun, H.: Text Mining in Qualitative Research: Application of an Unsupervised Learning Method. Organizational Research Methods 12(3) (2009)

17. Vatanen, T., Paukkeri, M., Nieminen, I.T., Honkela, T.: Analyzing authors and articles us-ing keyword extraction, self-organizing map and graph algorithms. In: Proceedings of the AKRR 2008, pp. 105-111 (2008)

18. Howard, K., Sharp, J.: The Management of a student research project (1983)

19. Melnyk, A., Handfield, R.: May you live in interesting times.. the emergence of theorydriven empirical research. Journal of Operation Management (1998)

20. Volpentesta, A.P.: Hypernetworks in a directed hypergraph. European Journal of Operational Research 188, 390-405 (2008)

21. Wacker, J.G.: A definition of theory: research guidelines for different theory-building research methods in operations management. Journal of Operations Management 16 (1998)

22. Romero, D., Galeano, N., Molina, A.: A Virtual Breeding Environment reference model and its instantiation methodology. In: Camarinha-Matos, L.M., Picard, W. (eds.) Pervasive Collaborative Networks. Springer, Boston (2008)

23. Camarinha-Matos, L.M., Afsarmanesh, H.: Collaborative Networks: Value Creation in a Knowledge Society. In: Knowledge Enterprise. IFIP, vol. 207, pp. 26-40. Springer, Boston (2006)

24. Jeong, K.Y., Wu, L., Hong, J.D.: IDEF method-based simulation model design and development. Journal of Industrial Engineering and Management 2(2) (2009)

25. http://www.pro-ve.org

26. Camarinha-Matos, L.M., et al. (eds.): Pro-VE 2005 IFIP Vol. 185, Pro-VE 2006 IFIP Vol. 224, Pro-VE 2007 IFIP Vol. 243, Pro-VE 2008 IFIP Vol. 283, Springer, Boston, Pro-VE 2009 IFIP Vol. 307. Springer, Heidelberg

27. Schmoch, U., Schubert, T.: Sustainability of incentives for excellent research - The Ger-man case. Scientometrics 81(1), 195-218 (2009)

28. Altman, D.G.: Sustaining Interventions in Community Systems: On the Relationship Between Researchers and Communities. Health Psychology 14(6), 526-536 (1995)

29. Lee, Y.S.: The Sustainability of University-Industry Research Collaboration: An Empirical Assessment. Journal of Technology Transfer 25, 111-133 (2000) 